\title{
CFD Analysis of a Solid Propellant Retro Rocket Motor using Ansys Fluent
}

\author{
Varada Anil Hemanth ${ }^{1, *}$ and U.S.Jyothi ${ }^{2}$ \\ ${ }^{1}$ P.G Student, Mechanical Department, GRIET, Hyderabad \\ ${ }^{2}$ Professor, Mechanical Department, GRIET, Hyderabad
}

\begin{abstract}
A Solid propellant Retro Rocket Motor with a C-D Nozzle is analyzed using Ansys Fluent 17.1. Steady State analysis of a retro rocket motor has been done for Viscous models like Inviscid and k- $\epsilon$ (Realizable) with air and gas as working fluids. The dimensions and the boundary conditions of the nozzle are kept consistent for both the viscous models to compare the exit parameters to theoretical values obtained by using one dimensional equations. The results obtained shows that the exit temperature of the nozzle in Inviscid viscous model is higher than theoretical value by $2.2 \%$ and for $\mathrm{k}-\epsilon$ viscous model it is higher by $5.4 \%$ with gas as working fluid.
\end{abstract}

\section{Introduction}

A Retro Rocket Motor essentially consists of a solid or liquid propellant and a C-D nozzle. It is used to decelerate the vehicle by firing in the direction of motion for a short period of time. For a spacecraft in orbit around the earth, retro rockets are fired to lower their orbit and re-enter earth's atmosphere. Without retrograde firing the spacecraft remains in its orbit until it loses altitude naturally in its own time. A retro rocket motor is also used in project Gemini, Apollo program, Space shuttle program and landers etc. In recent developments retro rockets are used in reusable launch systems. For efficient functioning of a retro rocket motor the C-D nozzle plays a vital role. It requires an optimum expansion nozzle for effective application. In supersonic flows through the divergent sections sometimes shocks occur due to adverse pressure gradient and irrelevant back pressure. To simulate flow through nozzle various viscous models are available in Ansys software. Inviscid model is close to an ideal flow neglecting viscous effects. But in reality no flow is ideal in nature. All the fluids are viscous and compressible in nature. To simulate a real Turbulent flow we choose $k-\epsilon$ viscous model.

The $\mathrm{k}-\epsilon$ viscous model uses two equations to solve for the parameters [1].Various investigations are done on flow analysis through C-D nozzle for supersonic flows. CFD analysis of Rocket Engine Nozzle to determine the effect of divergent angle on exit mach number [2]. Analysis of Flow in C-D Rocket engine nozzle using CFD where $\mathrm{k}-\epsilon$ turbulence model is used to simulate flow[3].Design and flow of C-D nozzle using CFD which concluded that to obtain higher propulsion for the rocket engine the divergence angle is $14^{0}-15^{0}$ [4]. CFD
Analysis of Compressible flow through ConvergentConical Nozzles. The effect of the nozzle pressure ratio and nozzle angle on the nozzle performance was investigate [5]. Comparative studies on various turbulent models with liquid rocket nozzle through computational tool was conducted [6] which concluded that the standard $\mathrm{k}-\epsilon$ turbulence model provided the accurate results as compared to Spalart-Allmaras model and Komega for same set of conditions. Turbulence modelling for gas flow in two-dimensional convergent-divergent rocket nozzle is numerically predicted and the associated physical phenomena are investigated for various operating conditions [7]. In previous studies softwares like gambit and fluent are used to design of nozzle and flow analysis respectively [8] to understand the air flow in conical nozzles. Numerical methods are also implemented in several cases to evaluate the simulated flow using fluent software $[9,10]$. To achieve good simulation results meshing plays an important role. The type of mesh and number of divisions influence the outcome of simulations. Analysis over a convergent divergent rocket nozzle which is performed by varying the number of divisions in mesh. The results indicated that the number of mesh divisions influence the accuracy of the results [11].

The main purpose of this analysis is to obtain exit parameters of the nozzle Pressure, temperature and Velocity for a turbulent $k-\epsilon$ viscous model and to compare them with Theoretical values. Analysis is also carried out for Inviscid model for both Air and Gas as working fluids and compared to theoretical values. 


\section{Methods and Materials}

\subsection{Theoretical Equations}

The operating condition of the nozzle depends on the geometry of the solid propellant. A solid propellant is used in a retro rocket to provide high thrust in less amount of time which depends on grain geometry. The grain shape and size depends on the application of rocket motor. There are different types of grain geometries such as circular, tubular, star shaped, etc. In this analysis a circular grain geometry is used. It has an outer radius of $52 \mathrm{~mm}$ and inner radius of $12 \mathrm{~mm}$ and length of $87 \mathrm{~mm}$.

The solid propellant is a double base with mass of $2 \mathrm{~kg}$ having a density of $1770 \mathrm{~kg} / \mathrm{m}^{3}$. The combustion of propellant is done by internal burning. The burn area is calculated using the relation

Burn area $A_{b}=\pi * \mathrm{~L} *(\mathrm{OD}+\mathrm{ID})$

\section{Where \\ $\mathrm{L}=$ length of propellant $=87 \mathrm{~mm}$ \\ $\mathrm{OD}=$ outer diameter \\ $\mathrm{ID}=$ inner diameter}

The burn rate of the propellant is determined using the relation

$$
\begin{aligned}
& \text { Burn rate } \mathrm{BR}=a P_{c}{ }^{n} \\
& \text { Where } \\
& \begin{array}{l}
a=\text { burn rate co-efficient }=2.73 \mathrm{e}-05 \\
n=\text { pressure exponent }=0.375
\end{array}
\end{aligned}
$$

The values of a and $\mathrm{n}$ are found empirically.

Chamber pressure $P_{c}=$

$$
1-n \sqrt{\frac{\mathrm{a} * \text { Burn area } * \rho_{p} * \text { characteristic velocity }}{\text { Throat Area }}}
$$

Characteristic velocity $=1300 \mathrm{~m} / \mathrm{s}$

Density of propellant:

$$
\rho_{p}=1700 \mathrm{~kg} / \mathrm{m}^{3}
$$

For an ideal gas and isentropic flow the stagnation properties of the nozzle remains constant. The relation between stagnation and exit static properties at a given mach number is calculated using relations given below.

$$
\begin{aligned}
& \frac{T_{0}}{T_{e}}=\left[1+\frac{(\Upsilon-1)}{2} M_{e}^{2}\right] \\
& \frac{P_{0}}{P_{e}}=\left[1+\frac{(\Upsilon-1)}{2} M_{e}^{2}\right]^{\frac{\Upsilon}{\Upsilon-1}} \\
& \frac{\rho_{0}}{\rho_{e}}=\left[1+\frac{(\Upsilon-1)}{2} M_{e}^{2}\right]^{\frac{1}{\Upsilon-1}}
\end{aligned}
$$

The ratio of Exit area to throat area can be specified by the Exit Mach number:

$$
\frac{A_{e}}{A_{t}}=\frac{1}{M_{e}}\left[\frac{2}{\Upsilon+1}\left(1+\frac{(\Upsilon-1)}{2} M_{e}^{2}\right)\right]^{\frac{(\Upsilon+1)}{2(\Upsilon-1)}}
$$

From isentropic relations the exit velocity of the fluid is given as:

$$
V_{e}=\sqrt{\frac{2 \Upsilon}{\Upsilon-1} \cdot \frac{R T_{0}}{M_{e}}\left[1-\left(\frac{P_{e}}{P_{0}}\right)^{\frac{\Upsilon-1}{\Upsilon}}\right]}
$$

rom (1) we get burn area to be $0.03498 \mathrm{~m}^{2}$ and from (2) the chamber pressure is found to be nearly 130bar. The stagnation temperature $\left(\mathrm{T}_{0}\right)$ is $2000 \mathrm{~K}$. Using these stagnation values the static values of pressure and temperature are calculated using relations (3) and (4). For Air the ratio of specific heats $(\Upsilon)$ is 1.4 and for Gas it is taken as 1.2

\subsection{Modeling Geometry}

The 2-D sketch of a rocket motor with C-D nozzle is generated using ANSYSWorkbench17.1.The dimensions of the sketch are given in Table. 1

\begin{tabular}{|l|l|}
\hline Inlet diameter & $30.5 \mathrm{~mm}$ \\
\hline Throat diameter & $11 \mathrm{~mm}$ \\
\hline Exit diameter & $17 \mathrm{~mm}$ \\
\hline Radius of convergent section & $9 \mathrm{~mm}$ \\
\hline Divergence angle & $13.5^{\circ}$ \\
\hline Nozzle length & $25 \mathrm{~mm}$ \\
\hline
\end{tabular}

Table 1: Dimensions of the nozzle

The 2-D surface of the sketch is generated. The surface is split into four faces along the length of the motor so that meshing can be done selectively. The surface model of geometry is shown in Fig.1

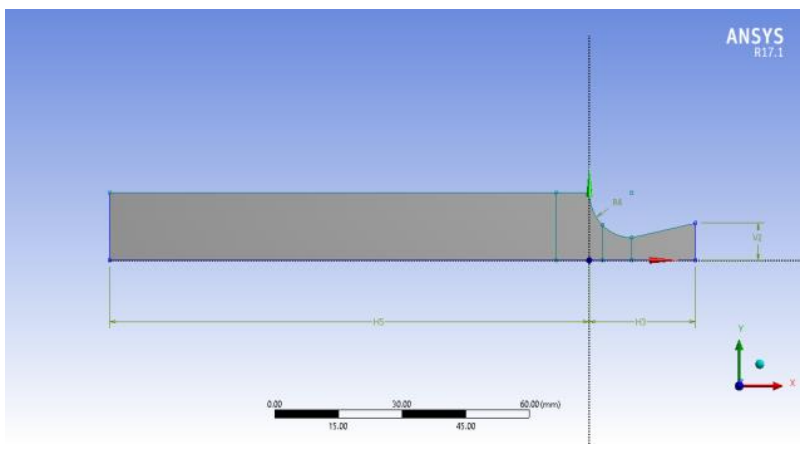

Figure 1: A split surface model of the rocket motor geometry

\subsection{Mesh generation}

A structured quadrilateral mesh is generated which is shown in Fig 2.Appropriate edge sizing is given to all the edges of the geometry. The number of nodes and elements formed are 98840 and 48724 respectively. The mesh settings are similar for both the viscous models to compare the results. Face sizing is applied to all the faces to obtain a structured mesh. 


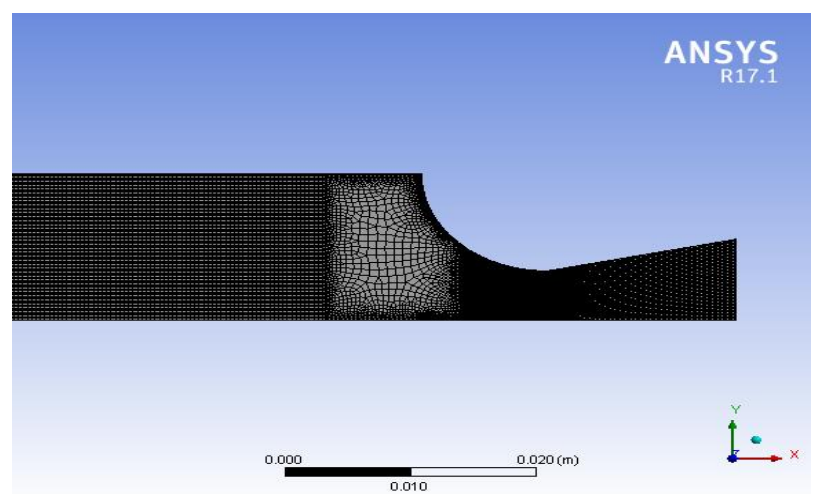

Figure 2: A structured quadrilateral mesh

\section{.2 .4 Setup}

In setup, double precision with parallel processing option is selected.

\subsubsection{General}

The solver type is set to Density-based to calculate the compressible effects of the fluid through C-D nozzle. The flow is symmetric about $\mathrm{X}$ axis so 2-D space is set to Axisymmetric. Gravity effects are neglected

\subsubsection{Models}

The energy equation is turned $\mathrm{ON}$ for all the flow analysis. For Ideal flow conditions the viscous model is set to Inviscid. To simulate a turbulent flow $\mathrm{k}-\epsilon$ (Realizable) viscous model is used.

\subsubsection{Materials}

The simulations are carried out for both Air and Gas as working fluids. The properties of the working fluids are given in Table 2

\begin{tabular}{|l|l|l|}
\hline \multicolumn{1}{|c|}{ Property } & Air & Gas \\
\hline Density $(\rho)$ & Ideal Gas & Ideal Gas \\
\hline Specific heat $\left(\mathrm{C}_{\mathrm{p}}\right)$ & $1005 \mathrm{~J} / \mathrm{kg} . \mathrm{K}$ & $1820 \mathrm{~J} / \mathrm{kg} . \mathrm{K}$ \\
\hline Thermal & $24.35 \mathrm{~W} / \mathrm{m} . \mathrm{K}$ & 0.183 \\
conductivity $(\mathrm{k})$ & & $\mathrm{W} / \mathrm{m} . \mathrm{K}$ \\
\hline $\begin{array}{l}\text { Molecular } \\
\text { viscosity }(\mu)\end{array}$ & $1.716 \mathrm{e}-05 \mathrm{~N} . \mathrm{s} / \mathrm{m}^{2}$ & $6.45 \mathrm{e}-05$ \\
\hline $\begin{array}{l}\text { Ratio of specific } \\
\text { heats }(\Upsilon)\end{array}$ & 1.4 & N.s $/ \mathrm{m}^{2}$ \\
\hline
\end{tabular}

Table 2: Properties of Air and Gas

\subsubsection{Boundary Conditions}

The following boundary conditions were used:

\begin{tabular}{|l|l|}
\hline $\begin{array}{l}\text { Inlet(Pressure-Inlet) Total Gauge } \\
\text { Pressure }\end{array}$ & $130 \mathrm{bar}$ \\
\hline Initial Gauge Pressure & $129.66 \mathrm{bar}$ \\
\hline Inlet Temperature & $2000 \mathrm{k}$ \\
\hline Pressure of Operating conditions & $0 \mathrm{bar}$ \\
\hline Outlet Pressure, temperature & $0 \mathrm{bar}, 300 \mathrm{k}$ \\
\hline
\end{tabular}

Table 3: Boundary conditions

\section{Results and Discussion}

The simulation of flow is carried out under Steady state condition. Contours of Pressure, Temperature and velocity are obtained. The average values of the Parameters at the nozzle exit plane are noted down using a probe. In this section the variations in pressure, temperature and velocity of Air and Gas for Inviscid and $\mathrm{k}-\epsilon$ viscous model are discussed and compared to theoretical values obtained.

\subsection{Pressure}

The Pressure contours generated are shown in Fig.3, Fig4, Fig.5 and Fig.6. The exit values of pressure for different models are represented in graph which is shown in Fig.7. For Air, pressure obtained in Inviscid model is similar to theoretical value with an error of $0.07 \%$ whereas for $\mathrm{k}-\epsilon$ model it is $10.9 \%$ higher than theoretical value. For Gas, pressure obtained in Inviscid model is less than Theoretical value by $5.2 \%$ and for $\mathrm{k}-\epsilon$ model is more by $11.5 \%$. The values obtained for $\mathrm{k}-\epsilon$ model is higher than Inviscid model and theoretical values for both air and gas.

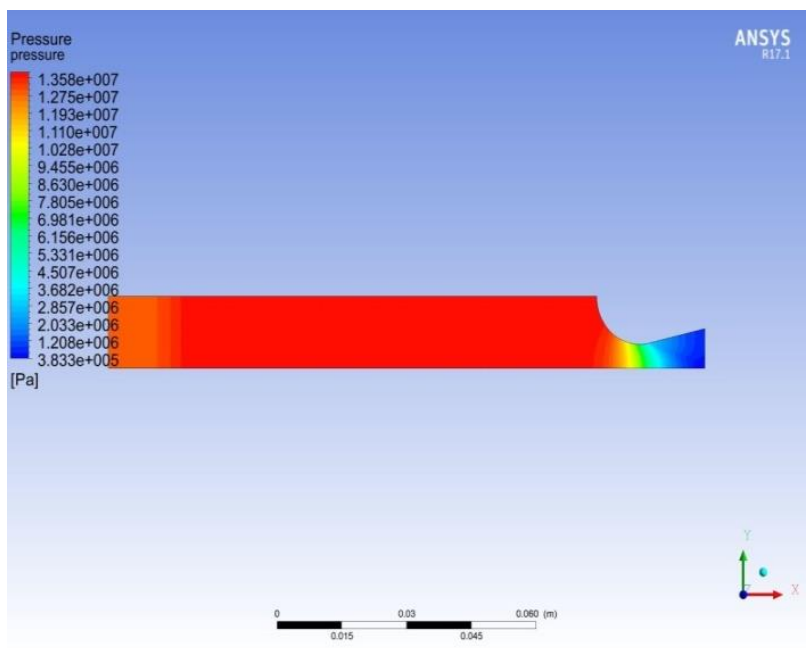

Figure 3: Pressure contour of Air for Inviscid model 


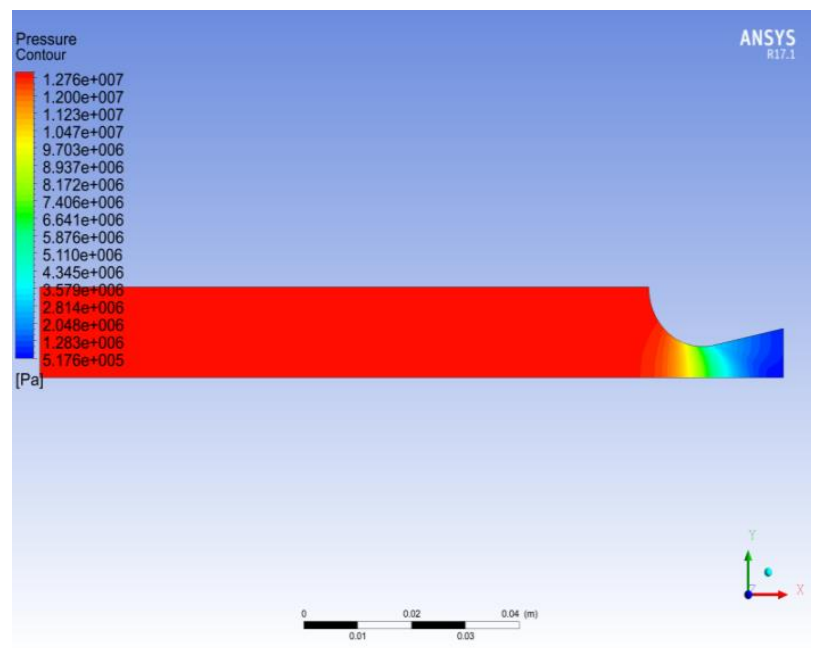

Figure 4: Pressure contour of Air for k- $€$ viscous model

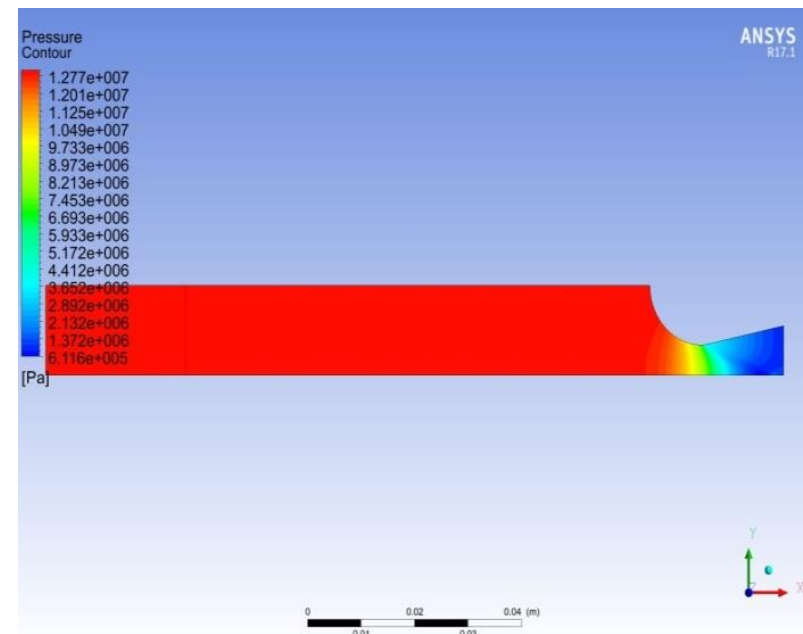

Figure 5: Pressure contour of Gas for Inviscid model

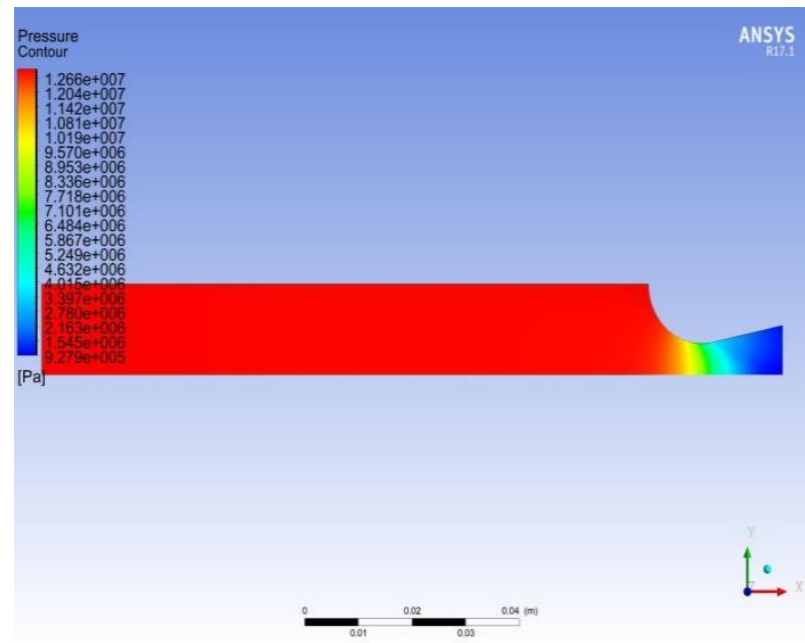

Figure 6 : Pressure contour of Gas for k- $€$ viscous model

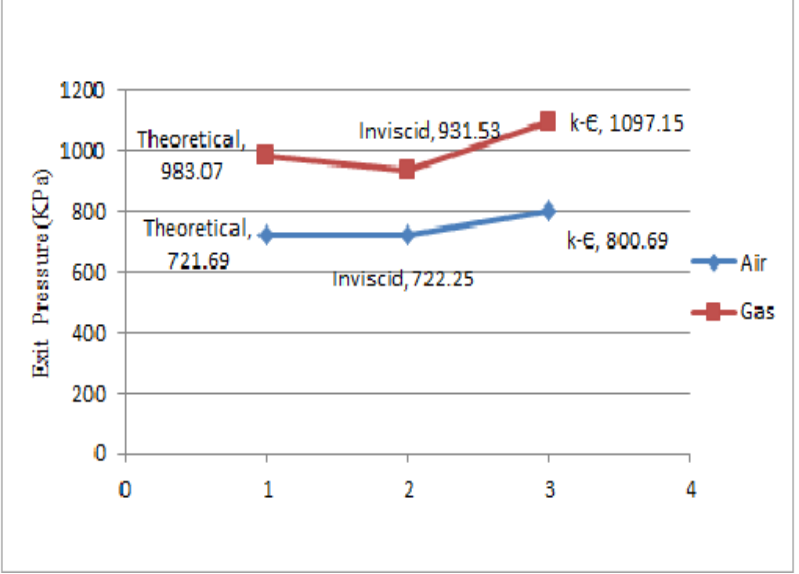

Figure 7: Comparison of Air and Gas exit pressures

From the simulation results it is shown that the expansion of flow in C-D nozzle is optimum. The pressure reduces from convergent section to exit plane of divergent section. This shows that there is no shock formation inside the nozzle. As the pressure drops along the length of the nozzle the temperature also drops. On the other hand the velocity of the fluid increases along the length of C-D nozzle due to conservation of energy.

\subsection{Temperature}

The temperature inside the combustion chamber is around 2000K. Fig.8 and Fig.10 shows contours of temperature for Inviscid model of Air and gas respectively. Fig.9 and Fig.10 shows temperature contours of Air and Gas respectively for $k-\epsilon$ viscous model.

For Air, Temperature obtained in Inviscid model is slightly higher than theoretical value by $4.3 \%$ whereas for $\mathrm{k}-\epsilon$ model it is $8.5 \%$ higher than theoretical value. For Gas, temperature obtained in Inviscid model is higher than theoretical value by $2.2 \%$ and for $\mathrm{k}-\epsilon$ model is more by $5.4 \%$.

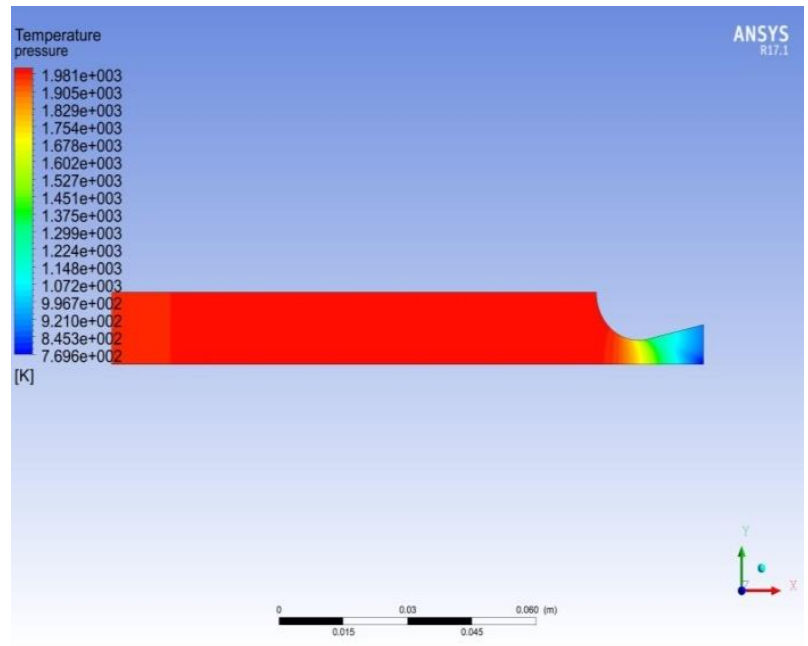

Figure 8: Temperature contour of Air for Inviscid model 


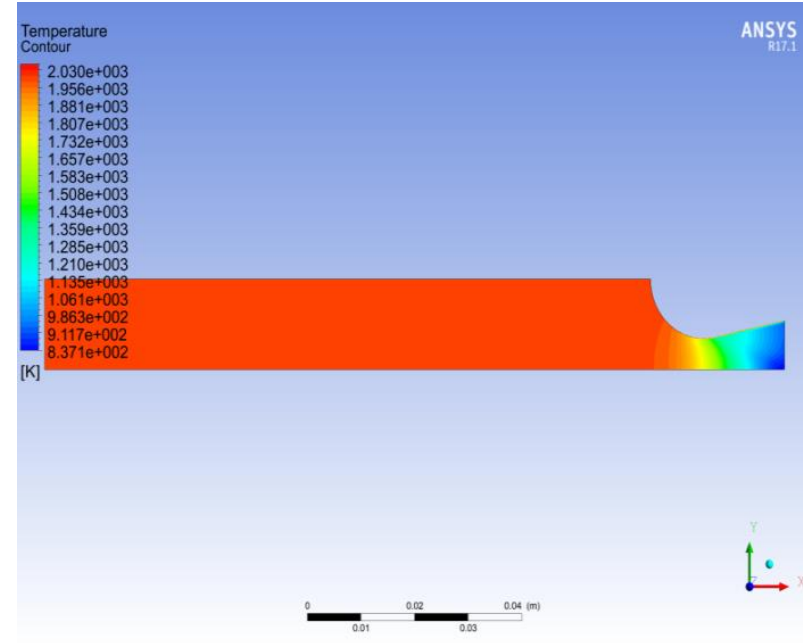

Figure 9: Temperature contour of Air for k- $\epsilon$ viscous model

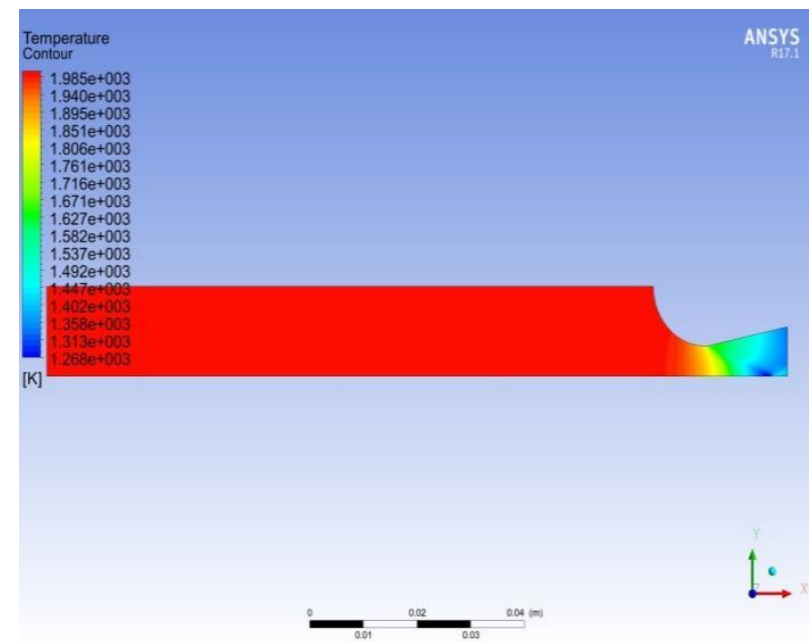

Figure 10: Temperature contour of Gas for Inviscid model

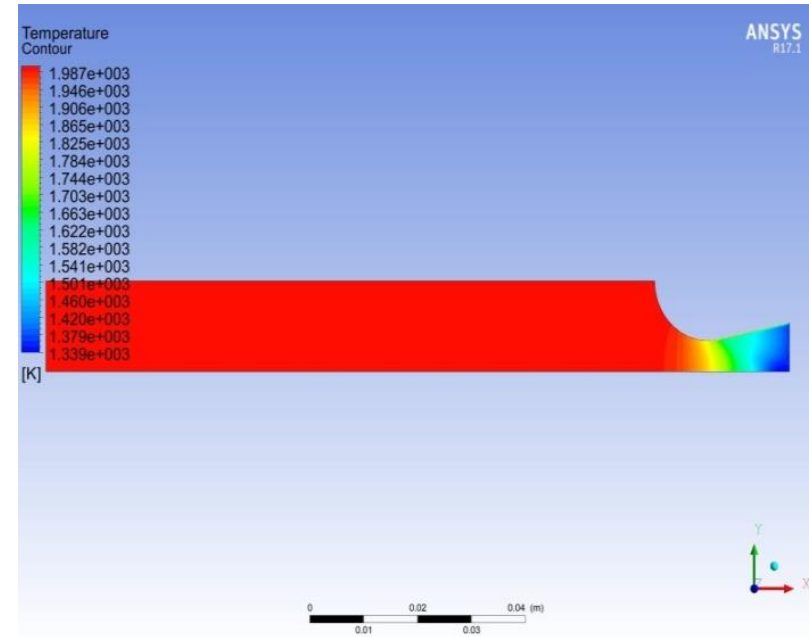

Figure 11: Temperature contour of Gas for $k-\epsilon$ viscous model

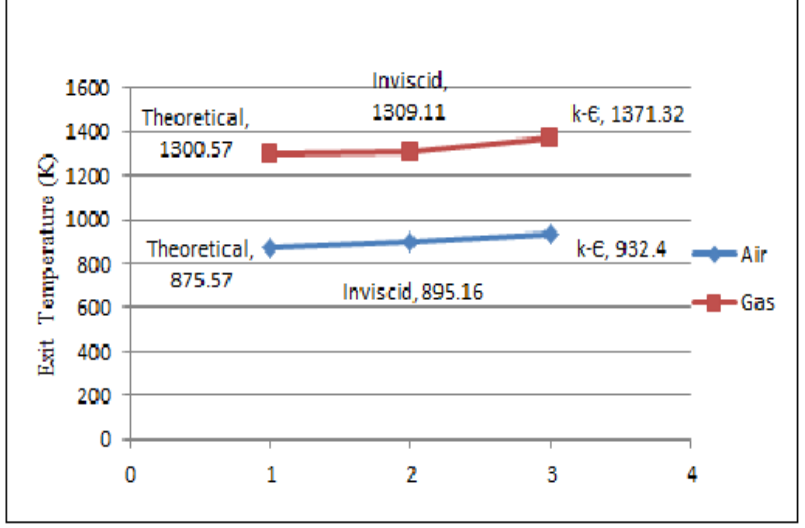

Figure 12: Comparison of Air and Gas exit Temperatures

From Fig. 12 it is seen that the temperature values at exit plane of nozzle are higher for Gas when compared to Air in all the viscous models. This is because the Specific ratio of Gas is lower than Air.

\subsection{Velocity}

Fig.13 and Fig.15 shows contours of velocity for Inviscid model of Air and gas respectively. Fig.14 and Fig. 16 shows velocity contours of Air and Gas for k- $\epsilon$ viscous mode respectively. Fig. 17 shows velocity values at nozzle exit plane for theoretical, Inviscid and $\mathrm{k}-\epsilon$ viscous model. For Air velocity obtained in Inviscid model is similar to theoretical value with a slight difference of $0.7 \%$ whereas for $\mathrm{k}-\epsilon$ model it is $2.5 \%$ lower than theoretical value. For Gas, velocity obtained in inviscid model is less than Theoretical value by $0.8 \%$ and for $\mathrm{k}-\epsilon$ model by $5.2 \%$.

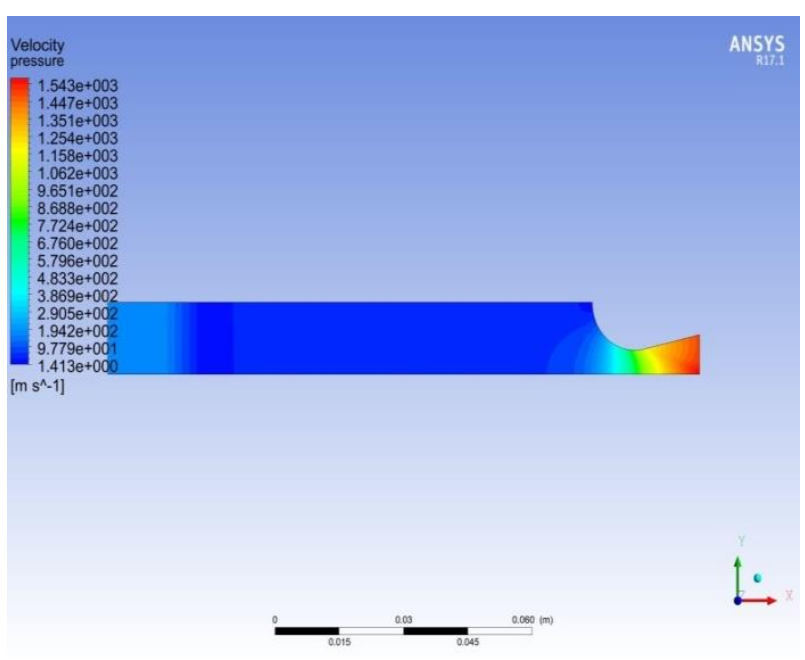

Figure 13: Velocity contour of Air for Inviscid model 


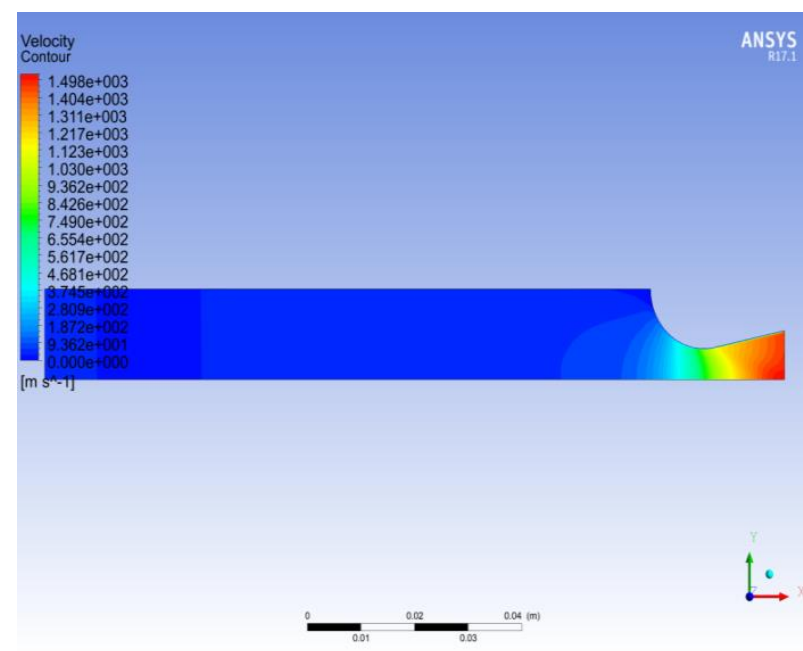

Figure 14: Velocity contour of Air for k- $€$ viscous model

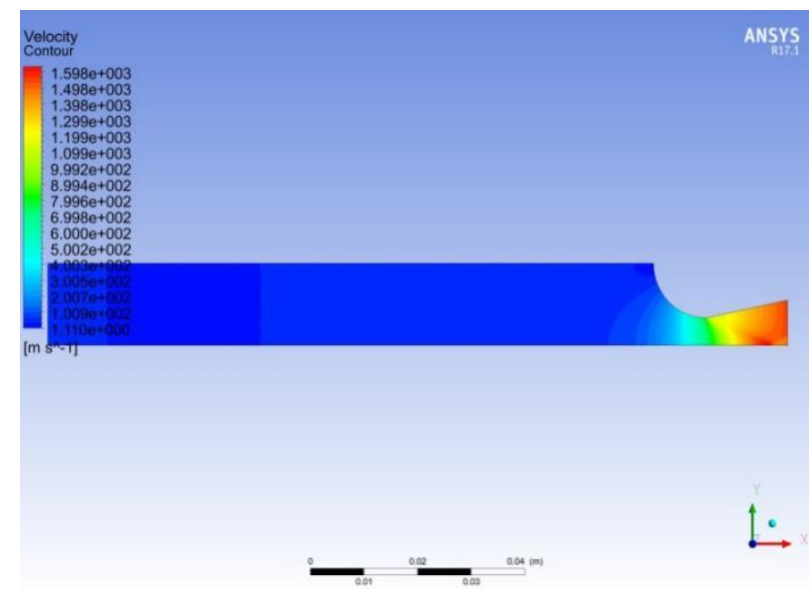

Figure 15: Velocity contour of Gas for Inviscid model

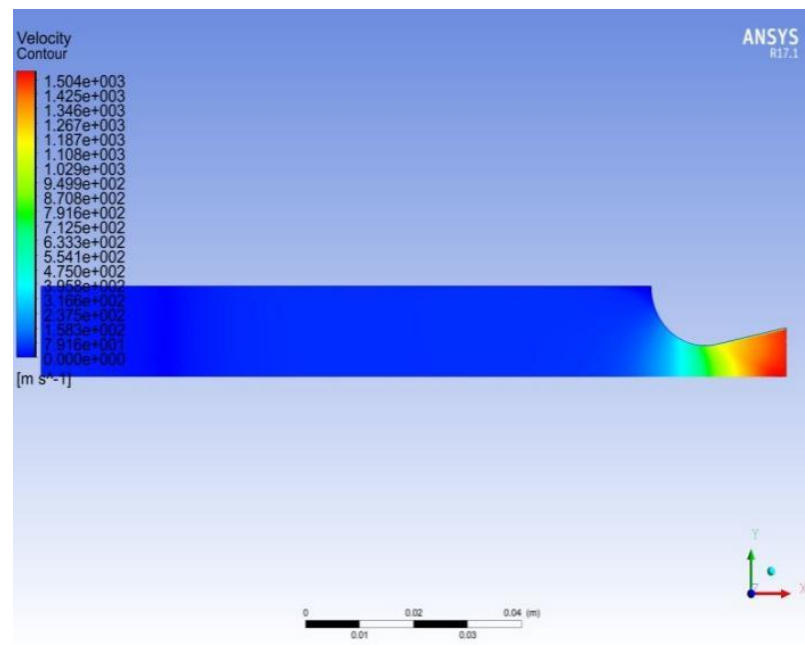

Figure 16: Velocity contour of Gas for k- $\epsilon$ viscous model

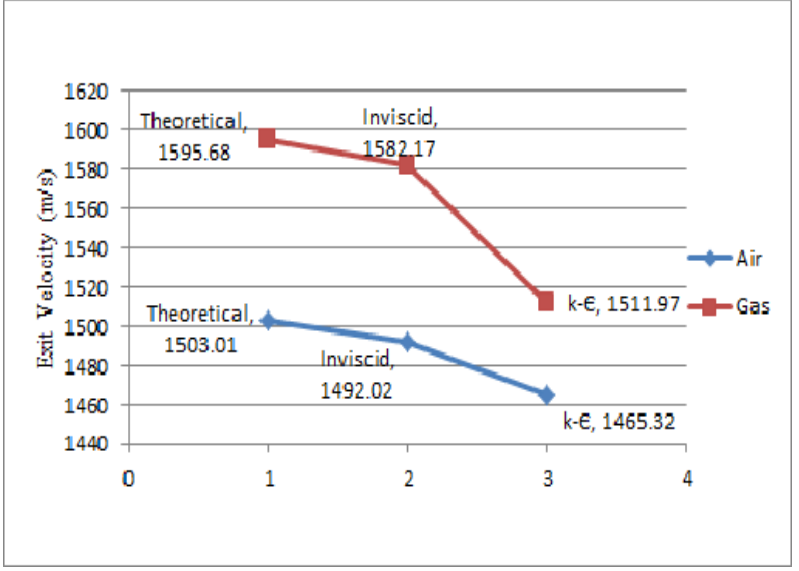

Figure 17: Comparison of Air and Gas exit Velocities

The results obtained for Inviscid model are approximately equal to Theoretical values since the assumptions are similar. The theoretical equations are derived based on the assumptions that the flow is steady, Inviscid, compressible and one dimensional. On the other hand the results obtained for $\mathrm{k}-\epsilon$ viscous model the values are slightly different. This is because the $k-\epsilon$ viscous model uses two transport equations approach to calculate the required parameters. These equations consider the viscous effects of the fluid so the temperature obtained in this model is slightly higher than the other two models.

\section{Conclusion}

After successfully completing the simulations for Inviscid and $\mathrm{k}-\epsilon$ viscous models and theoretical values the exit parameters for $\mathrm{k}-\epsilon$ turbulence model are found to be higher than the other two models. When compared to theoretical values the value of pressure for $k-\epsilon$ viscous model does not vary by more than $11.5 \%$ whereas value of temperature for k- $\epsilon$ viscous model does not vary by more than $8.5 \%$ and velocity by $5.2 \%$.

Thanks to Dr.Brahmanandam, Director, SPSL, ASL, DRDO for providing an opportunity to do a project. This work is carried out under the guidance of PVNL Shyamala Devi, Scientist E ,SPSL, ASL, DRDO,HYD.

\section{References}

1. N. Akbar Najar, D Dandotiya, Farooq Ahmad Najar, Int J Eng Sci, 2

2. P.Roy, A.Mondal, Biswanath, Int J Adv Res Sci Eng Technol , 3, (2016)

3. Bogdan-Alexandru Belega, Trung Duc Nguyen International conference of scientific paper(2015)

4. S. Ramanjaneyulu, P. Sai Teja, B. S. S. Prudhvi, P. Ramesh Appalaraju, T. V. R. S. S. N. Prudhvi, Int J Res Appl Sci Eng Technol ,7 (2019) 
5. Nathan Spotts, Stephen Guzik yand Xinfeng 49th AIAA/ASME/SAE/ASEE Joint Propulsion Conference, July (2013)

6. N.K.MohamadTanveer, C.Mohanraj, K.Jegadeesan, S.Maruthupandiyan Adv Mat Res, 984-985 (2014)

7. Balabel, A.M. Hegab, M. Nasr, Samy M. El-Behery , Appl Math Model 35 (2011)

8. P.Natta, V.RanjithKumar, Dr.Y.V.Hanumantha Rao, Int J Eng Res Appl ,2 ( 2012)

9. K. Pougatch, M. Salcudean, E. Chan, B. Knapper, Chem Eng Sci,63(2008)

10. K.M. Pandey, and A.P. Singh, Int J Chem Eng Appl, 1, (2010)

11. K.P.S.Surya Narayana1, K.Sadhashiva Reddy IOSR-JMCE , 13, 58-65 (2016)

12. U.S. Jyothi and K.Vijay Kumar Reddy, Int J Amb Eng,10 (2019) 